\title{
Survey Methodology in Violence- prone Khayelitsha, Cape Town, South Africa
}

\author{
Ndodana Nleya and Lisa Thompson
}

\begin{abstract}
This article discusses the methodological challenges of a service delivery survey in Khayelitsha, a township in Cape Town, South Africa. The survey aimed to gain a better understanding of the relationship between citizen participation and the environmental challenges facing residents in this urban area. Khayelitsha is a township prone to violence. Encountering violence during fieldwork can alter the way researchers execute research, yet this often remains unacknowledged in 'objective social science', especially in probability sampling. The article examines the effects of the risk felt by researchers on the research method employed in quantitative surveys. It shows that deliberating on this aspect of the research process is both necessary and useful, especially in terms of recognising the need to factor fear or uncertainty into the ways in which research processes unfold.
\end{abstract}

\author{
1 Introduction \\ This article presents an appraisal of \\ methodological challenges of a service delivery \\ survey study in Khayelitsha, a township in Cape \\ Town, South Africa. The central goal of the \\ survey was to gain a better understanding of the \\ connections between urban environmental \\ challenges facing residents in the area and \\ citizen participation methods. Yet in doing so, \\ both the objective issue of Khayelitsha as a \\ violence-prone township, and the risk \\ subjectively felt by the researchers involved, had \\ to be factored into the research process. \\ Encountering violence during fieldwork can \\ undeniably alter the manner in which \\ researchers execute research, especially when \\ the researchers perceive themselves to be under \\ threat, yet this often remains unacknowledged in \\ 'objective social science', especially in probability \\ sampling. In a probability sample (as opposed to \\ a judgement sample), 'arbitrary' alterations, \\ even when based on expert opinion, are \\ considered undesirable, although pure \\ probability samples are a rarity (Deming 1950). \\ The subjective experiences of the researchers \\ and the 'researched' is more often explored in \\ relation to qualitative fieldwork.
}

This article examines the effects of subjectively felt risk on the research method employed in quantitative surveys. It shows that deliberating on this aspect of the research process is both necessary and useful, especially in terms of recognising the need to factor fear or uncertainty into the ways in which the research process unfolds, especially in the contexts of poor and marginalised communities living in informal housing and settlements.

While the survey research discussed here was buttressed by more qualitatively based fieldwork, this article does not attempt a detailed comparison of both the objective and subjective components of risk perception in relation to each. Most of the researchers' perceptions relied on for reflections about the quantitative process were not part of the qualitative process. A more detailed comparison of the impact of different methodologies on the researchers would necessitate a careful analysis of the construction of each of these processes that falls beyond the scope of this article. Suffice it to say that the very nature of the quantitative fieldwork process is to strive for a depersonalisation of the research, where in most cases qualitative research 
attempts to prioritise the personal, and works on the premise of high validity of information based on processes of building understanding with individuals and groups over time (Hawkesworth 1989; Mbilinyi 1992). Our survey fieldwork experience highlights the problems inherent in the depersonalisation of research, and the attendant latent issues of 'self' and 'other', as well as problems embedded in upholding the distinction between researcher and the researched in survey processes. Our research process highlights that the very process of constructing the specific spatial terrain for survey work - seen as so critical to ensuring the accuracy of 'the facts' - reinforced a sense of 'otherness' among some of the researchers. In our survey terrain - a poor urban area - understandings of risk and potential violence went hand in hand with the sense of 'being an outsider'.

Research in other contexts shows that these constructions of otherness, risk and violence in poor communities do not stem from the researchers and the research process only. Many poor communities across cultural contexts feel increasingly insecure in material, physical and psychological terms (Narayan et al. 2000), and international development feminist theorists highlight the gendered and class dimensions of insecurity (Tickner 1991; Marchand and Parpart 1995; Meyer and Prugl 1999). Our research supports these perceptions of insecurity from within poor communities themselves. While the understandings of insecurity may be generated from both the researchers and the researched, shared subjective understandings of threat and insecurity are less possible based on a survey research instrument.

Our discussion here also departs from an objectified discussion of methodology (LeeTreweek 2000; Meyer 2007; Drakopoulos 1994), typical of academic papers. Instead we try to highlight the evolution of the research as both an objective and subjective process, taking into account the objective aims of the research and how these were balanced out by the subjectivities of both the researchers and those interviewed. The notion of scientific objectivity especially as applied to disjunctures between quantitative and qualitative methodology is often played out as an epistemological battle. In articulating emotive issues relating to survey methodology, the intention is not to undermine established notions of 'scientific objectivity', especially in quantitative epistemology. Instead, it is to show that these ideas are sometimes predicated on what we see as an artificial notion of detachment (Lee-Treweek 2000; Hughes 2004; Meyer 2007). While it is clear from the literature on survey research that some researchers feel it is possible to carry out social science research and analysis with 'complete detachment' in the hope of achieving objective social science, our research has highlighted the ways in which value judgements are core to the formulation of research objectives and hypotheses (Drakopoulos 1994) and that ongoing value judgements are made in relation to the research, particularly in environments which fall far short of the classic Northern survey terrain.

Central to these value judgements is the fact that Khayelitsha is known to be crime ridden, and has a poor, and in some instances almost nonexistent, road infrastructure. Most residents do not have listed telephone numbers, relying on mobile phones if they have a phone at all. Exact probability sampling is thus quite difficult, even with GIS mapping, and shacks spring up daily, constantly altering the urban landscape. Phone interviews are not possible due to the lack of listed numbers, and safety concerns are paramount in the light of Khayelitsha crime statistics (Table 1). Other unexpected issues changed the scope of the survey. The initial approach of using a single researcher to conduct the interviews proved too time-consuming, as the interview process turned out to be complicated by safety issues. The researcher became demoralised and overwhelmed by the conditions he was exposed to on a daily basis. Bringing in other interviewers introduced new issues related to safety, as all of them were women, and some did not feel safe in certain areas of Khayelitsha. This in turn entailed revisiting our initial sampling technique to ensure a balance between safety concerns and accepted sampling techniques.

The discussion proceeds as follows: Section 2 provides a brief description of Khayelitsha, the study site. Section 3 provides some of the salient features of research in violent contexts from literature as well as the challenges encountered in the research process. Section 4 considers the effects of safety concerns on quantitative research. Some general conclusions are discussed in Section 5. 
Table 1 Khayelitsha crime statistics 2006/07

\begin{tabular}{lll}
\hline Crime & Number of incidents & Incidents per 100,000 \\
\hline Murder & 430 & 106 \\
Attempted murder & 230 & 57 \\
Rape & 512 & 126 \\
Drug related crimes & 674 & 166 \\
General theft & 2780 & 684 \\
\hline Source Cape Argus (5 July 2007). & & \\
\hline
\end{tabular}

\section{Khayelitsha: history and crime overview}

Khayelitsha is a sprawling township located some 35 kilometres south-east of Cape Town between the northern shoreline of the False Bay and the N2 highway. It consists of informal (shanty town) and formal brick housing. With its foundations in apartheid planning, Khayelitsha retains a marginalised and racial character to this day (Cook 1986; Van Heerden and Evan 1986; Du Toit and Neves 2007). As an island of surplus labour and poverty, it remains more connected to the rural Eastern Cape Province than the city within which it is located. Predictably, Khayelitsha provides one of the most violent settings in urban South Africa as indicated by the crime statistics in Table 1. Noteworthy from the crime statistics for 2007/08 is that Khayelitsha ranks among the top areas in South Africa for murder, rape, and aggravated robbery which tend to be concentrated in the so-called 'black mega-townships' (Cape Times 2008). The statistics in Table 1 give only the reported crimes in the area for the year April 2006 to March 2007. The second column showing rate per 100,000 of the population was calculated to facilitate comparison with other contexts, based on the reported population of 406,779 (PGWC 2005).

The rape statistics in particular should be treated with circumspection, as sexual violence against women is frequently under-reported in South Africa (Luyt 2008).

With respect to murder, Khayelitsha statistics are over two and a half times the South African average of 41 per 100,000. The South African figures are over 20 times the murder rates of Western Europe, which average below two per 100,000 .

The centrality of violent crime in people's livelihoods in Khayelitsha was further captured by responses to the question: '[i]n your opinion, what are the three most important problems facing Khayelitsha that the municipality and government should address?' Tellingly, 61 per cent of respondents put crime on a par with unemployment, which after housing are seen as the most central problems that the area faces (Table 2). Although crime is known to be a problem throughout the Cape Peninsula and particularly in poor areas, the priority given to crime by residents in Khayelitsha took us by surprise, perhaps reflecting our subjective notions of the tolerance of criminality in areas facing so many other problems relating to living conditions. This finding also helps to debunk the notion which the South African government has enforced over the last decade, that crime is not as much of an issue to the majority of South Africans as reported in the media. This study shows that it is one of the central obstacles to be overcome in poorly serviced areas such as Khayelitsha. The study process also highlights that the issue of violence and crime is always a central leitmotif in undertaking research in areas such as this, underlining the 'official' findings of the research.

The causes of crime and violence in townships are many and varied. The underlying factors of violent crime in Khayelitsha have been traced to poverty, transience of the population and historical lack of effective policing (Du Toit and Neves 2007). In an authoritative book on the crime crisis in South Africa, Altbeker (2007) enumerates a comprehensive list of causes of violent crime including poverty, unemployment and income inequality; the phenomenon of crime creating more crime; the history of violent oppression during apartheid and colonialism; and the decay of social fabric represented by 
Table 2 The most pressing problems affecting Khayelitsha

\begin{tabular}{lll}
\hline Issue & Responses (\%) & Respondents (\%) \\
\hline Unemployment & 21.6 & 60.8 \\
Municipal rates & 0.6 & 1.7 \\
Transport & 0.7 & 2.1 \\
Education & 2.2 & 6.2 \\
Housing & 22.5 & 63.6 \\
Electricity & 3.4 & 9.6 \\
Water & 7.8 & 22 \\
Sanitation & 5.8 & 16.5 \\
Refuse & 3.7 & 10.3 \\
Storm-water & 0.4 & 1 \\
Health & 1.5 & 4.1 \\
HIV/AIDS & 3.3 & 9.3 \\
Crime and security & 21.6 & 60.8 \\
Poverty & 1.9 & 5.5 \\
None & 0.2 & 0.7 \\
Other & 2.8 & 7.9 \\
\hline
\end{tabular}

alcohol and drug abuse (see also Porsel et al. 2008). Violent crime has not escaped even the film-makers, with an award winning version of the opera Carmen, U-Carmen eKhayelitsha, set against the violence, poverty and squalor of Khayelitsha.

In this section, we have described how violence is a ubiquitous feature of life in Khayelitsha. In the next section we provide a brief theoretical reflection on undertaking research in violent contexts and then proceed to enumerate the challenges that were faced in executing the study.

\section{Research in violent contexts - from theory to practice \\ 3.1 Undertaking research in violent contexts - theoretical reflections}

Research in violent contexts brings up a number of issues relating to data and the effect on people involved in the research (Craig et al. 2000;

McCosker et al. 2001). McCosker et al. (2001) use the term 'sensitive' research to enumerate a number of issues that create sensitivities in research. First, they discuss issues considered private, stressful or sacred such as death and sex. Second, they mention issues that raise fear or stigmatisation such as illegal behaviour in youth. Third, they raise issues that present a threat, such as areas subject to controversy or social conflict. Since this article reflects on undertaking research in violent contexts, it focuses on the last point: the threat of harm, both physical and psychological, and its effect on the research process and quality of output.

The Social Research Association (SRA) has a 'Code of Practice for the Safety of Researchers', which points out safety issues pertinent in carrying out fieldwork in contexts prone to violence (SRA n.d.). The code identifies a number of issues that researchers may face in the conduct of fieldwork, among which are the risk of physical threat or abuse, and psychological trauma. The code recommends a number of measures to reduce the risk of harm, principally clarifying the duty of care between the employee and employer; budgeting for measures to enhance security of the researchers in the field; incorporating safety aspects in the proposal and reducing exposure to risk as far as possible; assessing the study site for safety risk; recommending measures on methodological design, interview set-up, and precautions to 
minimise risk, in interviews and interview conduct; as well as providing ongoing support to fieldworkers and enforcing safety protocols. The guidelines are useful as a checklist for items requiring special consideration but are by no means exhaustive. They can however, still provide a basis on which safety considerations and research design can reflect the magnitude of threat encountered in conducting research in violent contexts.

\subsection{Research challenges related to violence in Khayelitsha}

As part of reconnaissance of the study areas, a historical and spatial analysis was undertaken to better understand the context of current dynamics in Khayelitsha. The following discussion details some of the challenges encountered in the study that relate to the violent character of the study area. Although in total, six people were involved in the actual interviewing process, half (150) of the interviews were conducted by one male researcher, after which five women interviewers were allocated different parts of the study site to do the remainder of the interviews. Three of these women were engaged through a local NGO.

The employment of women as research interviewers meant a need to take into consideration the vulnerability of women as targets of violent crime, especially rape and mugging. This is both an objective and subjective concern. In one case, the area to be sampled had to be modified slightly to reduce the safety concerns of the interviewer involved. For the other researchers, the fact that one of the women lived in Khayelitsha and knew it very well helped to avoid altering the sample area significantly. The women interviewers employed through the NGO insisted they were comfortable to conduct interviews in one of the most unserviced and unsafe areas in Khayelitsha, despite being from a neighbouring township. None of the women encountered any difficulty or felt significantly threatened during their interviews, according to the survey questionnaires and the debriefing sessions held after the interviews we conducted. Additional focus group work conducted at the same time by two of the same researchers as well as the principal project leader - a white woman - also went without incident. Subjective feelings of threat were acknowledged by the two researchers who do not live in Khayelitsha, particularly in driving in and out of Khayelitsha, although not while in the homes of the women interviewed. Gendered effects of violence thus need to be reflected upon in research activity as highlighted in Hughes (2004) and Lee-Treweek (2000). Our research process suggests that this need not affect the research in direct ways, and that women researchers who are familiar with specific environments, dangerous as they may be, are able to negotiate these spaces more effectively than either men or women who are unfamiliar with the environment. Clearly both subjective and objective constructions of 'insider and outsider' or 'self and other' do make a difference to the research process and subjective constructions of fear based on conceptions of 'otherness' did affect the research process to some extent.

An additional point of note in relation to notions of 'insider and outsider' is the way in which the research process incidentally problematised the politically-defined, homogeneous category of 'Black', a definition which many have argued may be politically correct, but which does not reflect local racial tensions in Western Cape. One of the interviewers engaged is a so-called 'coloured' woman. Although the researcher was extremely competent, and the most relevantly qualified of the interviewers, she felt the most threatened during the process of conducting interviews. The sample area had to be modified to attend to her concerns of venturing too deep into 'shack land', the name given to those areas where shack density makes visibility and access very difficult. The interviewer also voiced concerns about residents modifying their answers because they wished to give her a certain impression of their lifestyles.

Thus, while race and gender could be viewed as a distinct form of 'othering', especially in the context of South Africa where hegemonic notions of masculinities transcend the whole fabric of society, it is important to underline that safety concerns are spread across gender lines although subjectively assumed to be largely a female phenomenon in areas such as Khayelitsha.

An important part of risk reduction in Khayelitsha involved the appropriate dress code for fitting into the community. This was relatively easy for a male interviewer, whose 
dress style as a student clearly reflected low position in society, although a passer-by asked if he was a social worker, maybe due to visible paper-files. For female interviewers however, an acute sense of vulnerability was stressed in particular by the African interviewers from Gugulethu, especially relating to dress code and accessories such as jewellery and high-end mobile phones, which are often targets in street muggings. The interviewers arrived at the briefing meeting for the interviews impeccably dressed, which led to a joke about what to leave behind before tackling the area where they were to do interviews. Interestingly, if possibly anecdotally, one of the interviewers remarked that no jewellery was equally dangerous, as the tsotsis $^{1}$ did not take kindly to women not having jewellery on at all.

In only one instance was an interview discontinued once it became clear that the interviewee was either very agitated or simply potentially violent, and it was ironically the only male interviewer on the team who encountered this potential hostility. While the researcher in question simply discontinued the interview, he did not disclose the incident to his family for fear of their concerns for his safety. Thus, aside from the objective analysis of the risks involved, there were ongoing subjective modifications to the understanding of risks, on the part of individual researcher identity, but also their involvement in and commitment to the research.

\section{Effects of safety considerations on quantitative methodology}

Quantitative research methods rely on randomness of selection of research participants. Safety consciousness dictates that where safety of the research participants is a concern, all measures should be taken to reduce such risk without degenerating the sample into a convenience or purposive sample. In this light, it is important particularly for survey researchers to be inherently aware of the methodological implications of value judgements regarding safety, if these are to be justifiable within a random sampling framework, although there is an equally important requirement for debasing notions of inherent bias in replacements when they arise.

In undertaking the survey in Khayelitsha in general, and in focusing principally on the dense informal settlements, the issue of security was introduced, with the researchers feeling insecure on a number of occasions. In spite of this, the probability sampling was not, in our view, significantly jeopardised. It is crucial to note that the stratified random sampling frame was designed to have a sample composition ratio of 68:32 between informal and formal housing, respectively, and that despite safety issues, the sampling adhered to this ratio across the designated sites in Khayelitsha. Given that the informal settlements generally lack municipal services, a variable which the research was geared to investigate in relation to forms of citizen participation, it would have been imprudent to remove these sites from the study, even though they are more prone to violence. Thus, despite both objective and subjective interpretations of threat, it was still possible to ensure probability sampling. There were some adjustments with interviewers sampling further violence-prone areas. It is important to note that women interviewers who were from Khayelitsha and the neighbouring area felt more comfortable about conducting research in informal housing than any of the other researchers.

Given the constraints to providing a more nuanced understanding of lived realities in urban townships like Khayelitsha, we suggest that quantitative and qualitative methodologies can be combined in useful ways so as to fill in the interpretative gaps in understanding a random sample. The combination of facts based on a representative sample of a specific population combined with qualitative research, such as focus group work and qualitative questions which allow for more in-depth answers, enables the research to uncover deeper understandings of the issue under investigation.

\section{Conclusions}

Conducting quantitative research in violent contexts presents a particular set of challenges that arise from the impossibility of following through on standard methodological recommendations of sampling, given safety issues and risk perceptions on the part of researchers.

The analysis of the quantitative research process described here emphasises that even though survey research aims to depersonalise the survey fieldwork process, it remains a subjective experience for researchers. It may help to enforce feelings of difference and otherness 
between the researcher and the researched that play into perceptions of risk and fear. Ironically, the survey research process tends to be objectified in terms of how quantitative outputs are expected to be reported on and disseminated. Reflections on 'things not going quite to plan' in terms of the survey research process may also be interpreted by some to indicate inadequacies in the final product, instead of an honest appraisal of how research agendas and programmes need to be adapted in situ. For this reason there is, to our knowledge, not much discussion and analysis of the issues facing researchers in relation to undertaking

\section{Notes}

1 According to the South African Concise Oxford Dictionary (2002), 'tsotsi' is a black urban criminal. The origin of the word may be a

\section{References}

Altbeker, A. (2007) A Country at War with Itself: South Africa's Crisis of Crime, Cape Town: Jonathan Ball

Cape Argus (5 July 2007) 'Two Kinds of Hell'

Cape Times (1 July 2008) 'Nyanga is Murder Capital'

Cook, G.P. (1986) 'Khayelitsha: Policy Change or Crisis Response?', Transactions of the Institute of British Geographers 11.1:57-66

Craig, G.; Gorden, A. and Thornton, P. (2000) 'Safety in Social Research', Social Research Update, http://sru.soc.surrey.ac.uk/SRU29.html (accessed 11 June 2008)

Deming, W.E. (1950) Some Theory of Sampling, London: Constable

Drakopoulos, S.A. (1994) 'Economics and the New Physics: Some Methodological Implications', South Africa Journal of Economics 62.4: 333-53

Du Toit, A. and Neves, D. (2007) 'In Search of South Africa's "Second Economy", Africanus 37.2: 145-74

Hawkesworth, M. (1989) 'Knowers, Knowing, Known', Signs 13.3: 533-57

Hughes, R. (2004) 'Safety in Nursing Social Research', International Journal Nursing Studies, 41: 933-40

Lee-Treweek, Geraldine (2000) 'The Insight of Emotional Danger: Research Experiences in a Home for Older People', in Geraldine LeeTreweek and Stephanie Linkogle (eds), Danger survey research in violence prone communities in the South. Thus, while the strength of survey research methodology lies in being able to base findings on generalisable facts, it is also quite evident that this type of research does little to build subjective understandings between the researcher and the researched that are often so key to understanding the behaviour of groups and communities. In relation to working in communities confronting high levels of violence, it would seem that these subjective understandings are as important, if not more important, than the objective facts.

Sesotho corruption of zoot suit, with reference to the flashy clothes originally associated with tsotsis.

in the Field: Risk and Ethics in Social Research, London: Routledge

Luyt, D. (2008) 'The Underreporting of Sexual Violence against Women in the Camdeboo', unpublished MA thesis in Political and International Studies', Rhodes University, Grahamstown

Marchand, M. and Parpart, J. (eds) (1995) Feminism, Postmodernism, Development, London: Routledge

Mbilinyi, M. (1992) 'Research Methodologies in Gender Issues', in R. Meena (ed.), Gender in Southern Africa: Conceptual and Theoretical Issues, Harare: SAPES Trust

McCosker, H.; Banard, A. and Gerber, R. (2001) 'Undertaking Sensitive Research: Issues and Strategies for Meeting the Safety Needs of all Participants', Qualitative Social Research 2.1, qualitative-research.net/fqs/fqs-eng.htm (accessed 11 June 2008)

Meyer, K.M. and Prugl, E. (eds) (1999) Gender Politics in Global Governance, Boston: Rowman and Littlefield

Meyer, S.D. (2007) 'From Horror Story to Manageable Risk: Formulating Safety Strategies for Peace Researchers', Masters Degree in Peace and Conflict Transformation, Centre for Peace Studies, University of Tromsø, Norway

Narayan, D.; Chambers, R.; Shah, M. and Petesch, P. (2000) Voices of the Poor: Crying Out for Change, London: Oxford University Press 
South African Concise Oxford Dictionary (2002) South Africa: Oxford University Press

PGWG (Provincial Government of the Western Cape) (2006) Register Update 2005, Appendix C, www.capegateway.gov.za/other/2007/10/ kpru_appendix_c_published_oct_07.pdf (accessed 20 November 2008)

Porsel, D.; Hornberger, J. and Mbembe, A. (2008) 'Crime and Politics in Our Time', Wiser Review 3: 8-9

Social Research Association (SRA) (n.d.) Code of Practice for the Safety of Social Researchers,
London: Social Research Association, www.the-sra.org.uk/documents/word/ safety_code_of_practice.doc (accessed 11 June2008)

Tickner, Ann (1991) 'On The Fringes of the World Economy: A Feminist Perspective', Ch. 9, in Craig Murphy and Roger Tooze (eds), The New International Political Economy, Boulder, Colorado: Lynne Rienner Van Heerden, D. and Evans, R.J. (1986)

Khayelitsha: A People's Reality, Cape Town 